\title{
REVISTA LITERÁRIA DO CORPO DISCENTE DA UFMG: UM PERIÓDICO REVELADOR DE ESCRITORES
}

\author{
Enio Luiz de Carvalho \\ Biaggi* $^{*}$
}

* prof.eniobiaggi@gmail.com

Mestre em Teoria da Literatura (Lit. e outros Sistemas Semióticos) e Doutor em Literatura Comparada (Lit., História e Memória Cultural) pelo PÓS-LIT - FALE/UFMG.
RESUMO: Análise comparativa da Revista Literária do corpo discente da Universidade Federal de Minas Gerais (RL) abordando sua história, importância e relação com outros periódicos artísticos a ela contemporâneos. Neste estudo busca-se ressaltar a contribuição da revista para a formação do nosso cenário cultural, além de sua importância em revelar talentosos escritores da literatura brasileira, hoje autores consagrados. A revista foi um periódico que alcançou proporções internacionais e inteiramente produzida pelos alunos da Universidade Federal de Minas Gerais (UFMG) com incentivo da reitoria da instituição. Por ser um período de importantes acontecimentos no cenário político e, consequentemente, uma época de efervescência artística no âmbito cultural, os anos de 1965 a 1980, referentes às quinze primeiras edições da revista, constituirão o corpus deste trabalho.

PALAVRAS-CHAVE: Revista Literária; Periódicos; Corpo Discente; UFMG.
ABSTRACT: Comparative analyses of the Revista Literária do corpo discente da Universidade Federal de Minas Gerais (Literary Magazine of the Faculty members of the Federal University of Minas Gerais) approaching its history, importance and relation to other contemporary journals artistically oriented. This study aimed at highlighting this journal's contribution to the formation of our cultural scenario and the importance it had in revealing talented writers of Brazilian literature, who have become well known ones today. The Revista Literária was a journal produced by the students of the Federal University of Minas Gerais encouraged by the dean of this institution. Since it was a period of many important events in the political scenario and consequentially a time of artistic effervescence in the national sphere, the time from 1965 to 1980 which refer to the fifteenth first editions of the journal, will be the corpus of this paper.

KEYWORDS: Revista Literária; Journals; Student's Magazine; UFMG. 
1. Ao longo deste estudo a sigla $R L$ será utilizada para denominar o periódico.

\section{INTRODUÇÃO}

Ano de 1971. O escritor Luiz Vilela publicava seu romance Os novos, retratando uma geração de jovens intelectuais ainda inseridos no meio universitário, preocupados em fazer história e transformar a sociedade por meio da literatura. Escrito num contexto conturbado politicamente, período da ditadura militar no Brasil, esse livro é o retrato de como o próprio autor se reunia com outros estudantes, na própria instituição de ensino ou em bares da cidade, para discutir filosofia, política, arte, ciência, literatura.

Os novos é uma obra que registra os bastidores de autores que marcaram uma época, momento em que proliferou, em Minas Gerais, o boom de jovens contistas. Além do quadro político daquela época, que levou vários artistas a se organizarem e fundarem movimentos artísticos a fim de se manifestarem contrariamente ao sistema, o alargamento do número de suportes midiáticos destinados a veicular textos e ideias foi, de certa maneira, responsável pela ocorrência de um período fértil para nossa cultura.

Dentre os vários tipos de mídia existentes naquele momento, os periódicos (jornais, revistas, suplementos) foram, sem dúvida, um dos principais meios de circulação desses textos. Dentre as revistas de literatura, uma, em particular, merece destaque: a Revista Literária do corpo discente da UFMG $(R L){ }^{1}$ por ter sido um periódico exclusivo de estudantes universitários, justificando sua escolha como corpus para o desenvolvimento deste estudo. As dificuldades que os escritores em início de carreira, portanto ainda sem expressão, encontravam ao tentar publicar seus trabalhos muitas vezes levavam esses artistas a se organizarem e a criarem seus próprios meios de divulgação. Dessa mobilização, nasciam os periódicos, como jornais, revistas e folhetins artístico-literários. Alguns ainda editavam seus livros com recursos próprios, e depois percorriam bares, livrarias e eventos culturais da cidade tentando vender os exemplares para ter retorno financeiro e visando dar publicidade a seu trabalho.

Outro meio encontrado pelos artistas para divulgarem seus textos se davam pela participação em concursos literários. Além de ganharem premiações em dinheiro, os trabalhos dos escritores vencedores eram editados e publicados sob a forma de livros. Iniciava-se, dessa forma, o reconhecimento de seu talento enquanto autor. Escritores consagrados, de forma geral, possuem trabalhos premiados em concursos, que são eventos de valorização da cultura cujos avaliadores são formados por intelectuais de expressão. Esses críticos, ao selecionarem textos vencedores dos concursos, legitimam, por meio de seu discurso dotado de poder, ditando as tendências literárias do momento. Seus critérios de escolha - aspectos formais, estilísticos, conteudísticos, temáticos tendem a ser seguidos também por outros escritores, visando imergir nesse mercado. 
De modo geral, as revistas acadêmicas apresentam menor circulação dentre os usuários de bibliotecas que livros, tendendo a ficar, portanto, mais confinadas nas prateleiras. Pela periodicidade de suas publicações, jornais e revistas, diferentemente do que ocorre com os livros, trazem o que há de mais atual e, ao mesmo tempo, transitório, temporário, mas que revelam a tendência e a efervescência do momento. Com o advento de novas edições, os volumes mais recentes tendem a suprimir as anteriores, tornando-as obsoletas, ultrapassadas. Periódicos normalmente são bastante lidos enquanto novidade, devido a sua efemeridade e sua tendência vanguardista, transformando-se, posteriormente, em arquivos memorialísticos.

A importância do resgate deste periódico simboliza a retomada de parte da história da universidade, a partir de um grupo de escritores marcados, na mesma época, como "geração suplemento", atuando no Suplemento Literário do Minas Gerais. Esses personagens foram importantes para o momento, ajudando a difundir a cultura local e ideias por meio de textos. A revista ainda serviu de foco de resistência na luta contra a ditadura militar nos anos de chumbo. Enquanto acervo arquivístico, a $R L$ merece ser resgatada pelo que representou para a comunidade acadêmica, hoje funcionando como arquivo de uma parte da história literária mineira a não ser esquecida.

Andreas Huyssen aborda, criticamente, a angústia da sociedade contemporânea pela preservação da memória, individual e coletiva, por meio do arquivo, que desencadeou no fenômeno de explosão de produtos culturais e ações políticas, a partir de representações simbólicas como monumentos e museus. Essa necessidade de manter a memória viva estimulou, nesse contexto, a produção artística voltada basicamente para os grandes acontecimentos históricos, em especial aqueles relacionados a grandes narrativas, no sentido lyotardiano do termo, como as duas grandes guerras e o holocausto. ${ }^{2}$ Esse fenômeno permitiu a releitura desses grandes eventos, mesmo que alguns textos promovessem essa discussão sob o viés da espetacularização, como, por exemplo, nos casos dos filmes Titanic, de James Cameron, e La vita è bella (A vida ébela), de Roberto Benini, ambos de 1997.

A preservação da memória por meio de arquivos e museus enquanto formas de resgate e de retorno ao passado sofreu um boom na sociedade do final do século passado, principalmente a partir dos anos de 1960, em consequência do surgimento "de novos movimentos sociais em busca por histórias alternativas e revisionistas". ${ }^{3}$ Segundo Huyssen, "a procura por outras tradições e pela tradição dos 'outros' foi acompanhada por múltiplas declarações de fim: o fim da história, a morte do sujeito, o fim da obra de arte, o fim das metanarrativas." ${ }^{4}$ Essas questões levantadas pelo autor nos incitam a refletir sobre a importante função desempenhada pelos arquivos no momento em que as novas tecnologias tendem a apagar os rascunhos e a conviver com a memória de forma precária e efêmera.
2. Cf. HUYSSEN. Seduzidos pela memória, p. 10.

3. HUYSSEN. Seduzidos pela memória, p. 10.

4. HUYSSEN. Seduzidos pela memória, p. 10. 
5. DERRIDA. Mal de arquivo, p. 7.

6. Cf. SAID. Cultura e política, p. 37.
A simultaneidade no mundo pós-moderno aliado à globalização pode culminar numa verdadeira "antropofagia cultural", através de tensões que envolvem relações de poder. O fenômeno da globalização propõe a imposição de uma cultura hegemônica sobre as demais, desrespeitando-se a alteridade e a diversidade das minorias. $\mathrm{O}$ arquivo, por sua vez, ajuda a preservar a identidade de um povo, que luta pelo direito de "ser diferente".

Jacques Derrida conceitua etimologicamente "arquivo" como vocábulo proveniente do termo "arconte" - quem exerce o comando, detendo o poder sobre o objeto arquivístico -, simbolizando aquele que dispõe de informações, quem organiza uma história de acordo com seus interesses, acarretando na dupla raiz etimológica da palavra "arquivo" enquanto arkhe (começo e comando). ${ }^{5}$ A partir desse conceito, verifica-se que o arquivo pode ser utilizado para a reconstituição de algo que simbolicamente representa, a partir da perspectiva de quem o reconstrói, ou seja, de quem detém o poder, o arconte.

Enquanto elementos que visam à preservação da memória coletiva, ao lado de arquivos e museus, intelectuais também exercem papel preponderante nesse contexto social contemporâneo de preservação da memória. O teórico palestino Edward Said sustenta essa afirmativa utilizando, como exemplo, o caso dos modernistas brasileiros, intelectuais que falaram em nome daqueles que não tinham voz. ${ }^{6}$ Não há dúvidas de que o mundo está sendo musealizado e que um dos fatores que contribuiu para esse fenômeno foi a emergência da sensação temporal de final de século e de milênio, conforme afirma Andreas Huyssen. Ainda segundo ele, essa "cultura da memória" na qual estamos inseridos é fruto de interesses político-financeiros num contexto marcado pela espetacularização de grandes eventos históricos explorados pela indústria artística, por lutas locais frente à globalização.

O discurso da memória é marcado pela amnésia, apatia ou embotamento como consequência da mídia, "desde a imprensa e a televisão até os CDRoms e a Internet - que faz a memória ficar cada vez mais disponível para nós a cada dia."7 A partir desse contexto e diante da incerteza sobre se o excesso de memória é que acarreta no medo do esquecimento ou se é o medo do esquecimento é que alimenta o desejo de lembrar, Huyssen afirma que essa busca incessante pela preservação da memória não é apenas de um fenômeno individual, porém um processo coletivo, um fenômeno social. No entanto, ainda segundo ele, a ameaça do esquecimento é proveniente da própria tecnologia à qual depositamos uma enorme quantidade de registros e informações."

A memória é sempre transitória, notoriamente não confiável e passível de esquecimento; em suma, ela é humana e social. Dado que a memória pública está sujeita a mudanças - políticas, geracionais e individuais -, ela não pode ser armazenada para sempre, nem protegida em monumentos. ${ }^{9}$
7. HUYSSEN. Seduzidos pela memória, p. 18.

8. Cf. HUYSSEN. Seduzidos pela memória, p. 33.

9. HUYSSEN, Seduzidos pela memória, p. 37.
EM TESE
BELO HORIZONTE
v. 20
N. 3
SET.-DEZ. 2014
BIAGGI. Revista Literária do corpo discente da UFMG [...]
P. $199-210$ 
FIGURA 1

Capa da Revista Literária do corpo discente da Unversidade Federal de Minas Gerais (RL). Belo Horizonte, 1985-1989.

\section{A CRIAÇÃO DA REVISTA}

A $R L$ foi instituída em 1966, mesmo ano de criação do Suplemento Literário do jornal Minas Gerais e um ano antes do surgimento do Festival de Inverno da UFMG (1967), por três alunos da universidade - Plínio Carneiro, estudante de Sociologia, formado em Jornalismo pela Faculdade de Filosofia e assessor de imprensa do Reitor da UFMG; Luiz Gonzaga Vieira, aluno do curso de Letras, também formado em Jornalismo; e Luiz Vilela, acadêmico em Filosofia.
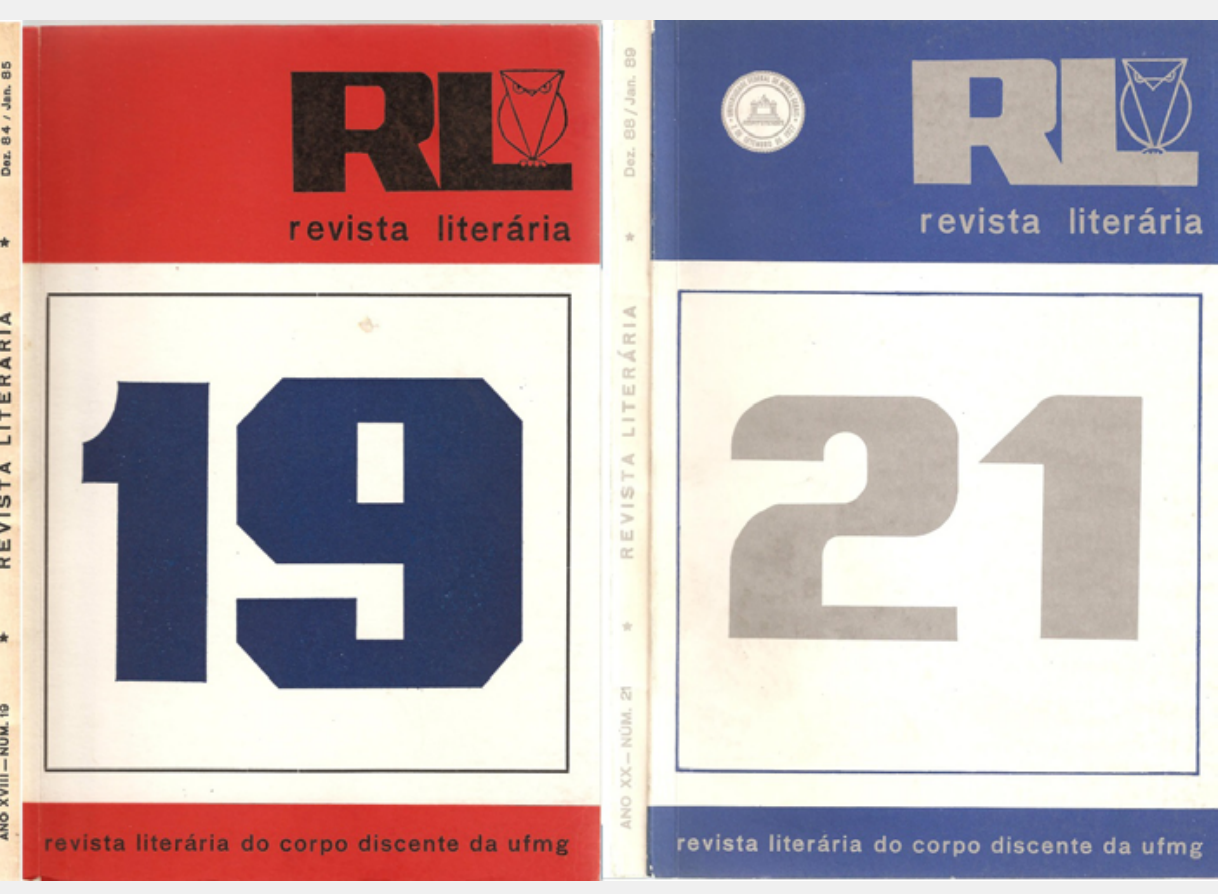

FIGURA 1
De caráter artístico e acadêmico, o periódico foi, nestes trinta anos de publicação, patrocinado pela Reitoria da UFMG. Em geral, apresentava divisão estrutural em duas partes: a primeira, contendo contos e poemas vencedores dos concursos - os três textos vencedores de cada modalidade seguidos de mais cinco trabalhos escolhidos como menção honrosa; a segunda parte, contendo os ensaios, contos e poemas de ex-alunos e professores da universidade, além da inserção, a partir da décima edição da revista, dos textos imagéticos premiados pelo concurso de ilustrações e da seção "Resenha", destinada a veicular informações acerca dos textos recebidos pelo Conselho Editorial, trazendo, inclusive, quadro com dados estatísticos. Ao longo de sua existência, o concurso da $R L$ recebeu 2.348 contos e 11.426 poemas. Foram, ao todo, 13.761 trabalhos de 3.507 estudantes da UFMG publicados em 26 edições do periódico. Sua divulgação alcançou âmbito internacional.

A partir dos anos de 1980, quando a universidade desviava seu foco para o advento dos cursos de pós-graduação, a $R L$ passou dar maior ênfase à publicação de ensaios acadêmicos. Esse tipo de texto que geralmente é produzido nas academias começou a ganhar força, passando a serem mais fundamentados e analíticos. Periódicos atuais vinculados às instituições de ensino superior normalmente objetivam a publicação de textos crítico-teóricos feitos pela comunidade universitária. 
$\mathrm{Na}$ realização desta pesquisa não foram encontradas revistas literárias universitárias criadas nos mesmos moldes da $R L$.

Um possível - e provável - retorno da RL, em formato eletrônico, seria viabilizado pelas diversas vantagens que a mídia digital proporciona sobre o texto impresso. Dentre esses aspectos, pode-se citar o fato gerar menos custo para a instituição, uma vez que não necessitaria de papel para imprimi-la; seria um periódico ecologicamente correto, em meio à escassez de papel nos dias atuais; a chance de obter maior alcance nas divulgações de suas edições é potencializada, tornando-se ainda mais acessível ao público que na época em que circulava na modalidade impressa; por ser um arquivo virtual, não há a possibilidade de se deteriorar com o tempo; isso sem contar com a facilidade de ser armazenada, uma vez que não ocupa espaço físico na estante, mas tão somente no hard disk do computador.

Dada sua importância para a cultura e para a academia, acredita-se que, da mesma forma que houve movimento entre alunos e professores da universidade na época da ditadura militar em prol da manutenção da revista, deveria emergir outro manifesto, agora a favor de seu resgate, devido ao que a revista simboliza e ao que representa para a instituição. Criada num momento de explosão literária em todo o Brasil, a $R L$ serviu de plataforma para universitários que se tornariam, mais tarde, importantes escritores e pesquisadores do nosso cenário acadêmico-cultural. Por esse motivo, a relevância desta pesquisa deve-se, sobretudo, a sua contribuição para a preservação da memória cultural e ao resgate histórico-literário, através da análise comparativa entre a revista e outros periódicos da época ou entre as obras posteriores de escritores hoje consagrados e seus primeiros trabalhos que nela foram publicados.

Durante a elaboração desta pesquisa, no entanto, alguns problemas vieram à tona dificultando seu desenvolvimento. Como exemplo, podemos citar o falecimento de autores importantes que publicaram na revista e a falta de acesso a outros, seja pela distância, seja por não ter conseguido localizá-los ou contatá-los. Também podemos somar a essas dificuldades a indisponibilidade ou a falta de interesse por parte de pessoas que por ela passaram, apagando sua história. A falta de arquivos que serviriam de dados para a realização desta análise, aliada à incerteza das pistas, foram, juntas, os maiores empecilhos com que me deparei nesta jornada. Como não há, ainda, nenhum texto teórico envolvendo o objeto deste estudo, não me restou outra alternativa senão reconstituir sua trajetória, traçando-se, assim, o seu perfil histórico.

Por ter sido a única do gênero (revista de cunho artístico-literário organizada exclusivamente por estudantes de uma instituição de ensino para publicar seus próprios trabalhos, contendo concurso artístico, comissão julgadora e premiações 
para os vencedores, apoiados pela Reitoria da própria universidade), foi necessário realizar um estudo crítico a respeito da posição que ocupam professor e aluno no meio acadêmico Como orientação para essa discussão, refletimos sobre as seguintes indagações: "Qual é o papel exercido por um discente numa universidade?", "Quais são as prerrogativas dos docentes e dos discentes?" " "Quantos veículos comunicacionais são disponibilizados pela instituição de ensino para dar voz aos estudantes, objetivando a propagação de suas ideias?"

É inegável a valorização dos currículos dos cursos e de profissionais a partir da quantidade e qualidade de publicações que promovem. No entanto, as instituições acadêmicas, de forma geral, oferecem poucos suportes, quando existentes, visando a dar publicidade aos trabalhos realizados pelos discentes. Mesmo em revistas de natureza acadêmica, muitas vezes se faz necessário que alunos insiram nomes de professores nos textos para receberem pareceres favoráveis à sua publicação. Por essas razões, a $R L$ foi importante instrumento comunicacional, por ter atribuído voz aos discentes. Assim, os estudantes, por disporem de pouco espaço para divulgar suas ideias, resolveram se organizar e fundar o periódico.

Atualmente, nas universidades, os alunos dispõem de veículos para publicarem seus textos, limitados, em geral à circulação de trabalhos acadêmicos - ressalto que não fo encontrado nenhum outro periódico impresso nos moldes da $R L$ voltado exclusivamente para divulgação dos trabalhos artísticos dos alunos, que seja organizado por discentes, patrocinado pela reitoria da instituição e premiando em espécie os autores premiados. A própria Faculdade de Letras da UFMG, apenas a título de exemplo, conta com a revista de periodicidade anual Em Tese, dedicada exclusivamente à publicação de artigos dos alunos do curso de pós-graduação, antes veiculada na versão impressa e atualmente circulando no formato eletrônico. Além dessa, encontramos a Revista TEIA, em formato eletrônico, vinculada à Câmara de Pesquisa da FALE/UFMG, que visa a publicar textos ficcionais, em prosa e poesia, traduções, crônicas e ensaios realizados a partir de temas e desafios propostos aos estudantes.

Hoje em dia poderíamos ler a $R L$ como uma revista que, mais do que um veículo de resistência à ditadura militar, também foi um grande divulgador da cultura local dos estudantes, ajudando a impulsionar a carreira de diversos escritores. Seus prêmios, além de destinarem gratificações pecuniárias para os vencedores - se levarmos em consideração o contexto de universitários, eram muito bem recebidos pelos jovens intelectuais - consistiam na publicação desses textos, impulsionando o reconhecimento de sua qualidade artística. Também poderíamos pensar, em termos de currículo, que a $R L$ seria uma excelente forma de preenchimento dos requisitos exigidos pelo mercado, sobretudo para aqueles que pretendem seguir carreira acadêmica. 
Podemos afirmar, ainda, que a $R L$ contribuiu significativamente para o boom literário de contistas e poetas mineiros, incentivando-os a pensar o espaço universitário e a cultura valorizando os trabalhos de estudantes jovens e talentosos, mediante publicações e premiações em dinheiro, destinada aos vencedores dos concursos por ela promovidos. O glamour, nas festas de premiações, em que os autores de textos vencedores dos concursos recebiam seus prêmios das mãos do reitor da UFMG, também impulsionava a produção literária e artística da época.

A universidade, dessa forma, refletia sobre si mesma enquanto valorizava a produção acadêmica e artística de seus alunos, por divulgar e publicar textos num periódico por eles organizado e por ela financiado (a $R L$ possuía apoio direto do gabinete da reitoria da universidade). Eram textos de estudantes universitários, intelectuais em ascensão, enquanto intelectuais e cidadãos preocupados com o cenário político-social em que se encontravam.

Os textos da revista eram destinados a uma elite intelectual. Seu público era composto por estudantes universitários, como os autores dos textos da $R L$, intelectuais espalhados pelo mundo e não por cidadãos comuns, conforme ficou demonstrado nas cartas que os responsáveis pela revista recebiam. Os cursos de extensão são uma tentativa de minimizar esse problema. São atividades que visam a reduzir as fronteiras existentes entre universidade e sociedade, tentando aproximá-las. Enquanto prestam um serviço social, as instituições de ensino viabilizam seu ensino, aperfeiçoando o processo pedagógico de ensino/aprendizagem com questões de ordem prática.

A revista retrata uma geração que não se deixava abater pelos problemas políticos, econômicos e sociais da época. Ao contrário, reflete uma geração que ficaria marcada pela resistência e oposição ao poder autoritário das ditaduras dos militares que assolavam a América Latina nos anos de 1960 e 1970. A RL, além de importante veículo cultural editada pelos discentes da Universidade Federal de Minas Gerais, nas décadas de 1960 a 1990, deve ser considerada, à sua maneira, consoante a sua proposta enquanto veículo midiático, um importante espaço de resistência política no período ditatorial.

Naquele momento de extrema repressão política, conhecido como "anos de chumbo", jovens intelectuais produziam seus textos artísticos densos de recursos estilísticos, a fim de não sofrerem as consequências da censura previstas naquele regime, mantendo discurso irônico e metafórico, característico da arte literária. É plausível pensar, por esse motivo, que as diversas tentativas de fechamento da revista naquele momento histórico tinham seus propósitos, afinal, não é comum censurar uma revista artística cujos textos, 
supostamente, não poderiam versar sobre temas de cunho político-partidário, conforme nota publicada pelo próprio periódico, uma vez que estes não teriam o condão de ofender a ordem pública.

A resistência, por parte dos professores e alunos, no estado de exceção, para o não fechamento do periódico não foi em vão. A revista perdurou até meados da década de noventa, quando enfrentou outro problema: a política financeira institucional. Em 1996, a $R L$ publicava sua última edição, pelo menos com esse nome. Por meio de uma entrevista realizada com o atual diretor do Conservatório de Música, Carlo Alberto Marques dos Reis, que trabalhou durante muitos anos na edição da revista, tomamos ciência da publicação de mais uma edição do periódico, porém com título diverso do original. Essa revista, denominada IPSIS, destoava-se do perfil da $R L$, pois se destinava apenas à publicação de textos ficcionais e acadêmicos de alunos da Faculdade de Letras da UFMG, e não de toda comunidade universitária.

Um dos prováveis motivos que determinou o fim da revista foi a adoção, naquela época, de uma política econômica de corte de gastos, privilegiando alguns segmentos institucionais em detrimento de outros. Alguns departamentos da universidade, com poucos recursos financeiros, tiveram que reestruturar seus orçamentos. Enquanto revista de caráter artístico - as universidades estão priorizando, atualmente, a produção acadêmica -, o periódico dos discentes teve sua sobrevivência comprometida por essa medida administrativa. A época em que a $R L$ foi extinta, meados da década de 1990, coincide com o advento da internet. Essa transformação na sociedade, que passou a viver da era da "cibercultura", acarretou, também, alterações nas expectativas acadêmicas. Qual seria o futuro do texto impresso - e, consequentemente, dos livros, jornais, revistas, etc. - na era digital? Qual seria o futuro dos periódicos de literatura nesse contexto? Deveria a $R L$ aderir a esse novo formato midiático, reestrutando-se, aderindo às novas tecnologias? É possível que esse tenha sido um dos pensamentos que tenham levado ao término do periódico ou que, pelo menos, tenha contribuído para seu fim.

A repercussão da proposta de retorno da revista em formato digital se apresenta como, no mínimo, sensata. Conforme já foi dito anteriormente, uma série de aspectos positivos viabilizaria sua retomada, como o baixo custo, a fácil acessibilidade, a ampla divulgação, a facilidade de arquivar, a não deterioração do material, dentre outros benefícios. Apesar de ser possível a retomada da revista na modalidade impressa, acredita-se que o perfil eletrônico se apresenta como forma mais viável por todos os benefícios de que dispõe, como a ampla divulgação na internet, a facilidade de armazenamento sem deterioração e preenchimento de espaço físico nas bibliotecas. 
Utilizando-se como parâmetro as estruturas da maioria dos textos vencedores dos concursos literários promovidos pela $R L$, é nítida a predileção, pelos membros integrantes de sua comissão julgadora, por uma literatura que apresentasse traços modernos, como crônicas de caráter menos informativo e mais narrativo, semelhante ao estilo dos contos e das novelas, contos que apresentam enredo fragmentado, linguagem mais distante do prolixismo da norma culta e mais próxima da oralidade; e por poemas esteticamente voltados à visualidade, inspirados pelo movimento Concretista.

Essa preferência não é exclusiva da comissão da $R L$, mas trata-se de uma tendência da estética contemporânea, oriunda da influência que exerceu a linguagem jornalística nos textos literários, conforme demonstrou Maurício Silva, no texto "Consagração e decadência do academicismo literário: o caso do jornalismo". Os textos que circulam em outros periódicos literários (suplementos, revistas, cadernos, etc.), contemporâneos à revista, também possuem, em geral, as mesmas características, conforme afirma Humberto Werneck, em seu artigo "Santa Sheerazade: padroeira dos jornalistas", publicado em 2012, numa edição especial do Suplemento Literário sobre jornalismo cultural. Além disso os textos vencedores de concursos literários da atualidade possuem essa formatação, tal como os textos de vários autores premiados pelo concurso da revista, o que sugere que os critérios utilizados pelas comissões julgadoras da revista - bem como suas predileções estético-literárias - são semelhantes aos de outros concursos.

\section{CONSIDERAÇÕES FINAIS}

O principal objetivo deste trabalho foi o de resgatar um periódico que se encontrava esquecido, abandonado nas prateleiras da biblioteca. Para tanto, foi necessário contextualizá-lo historicamente, analisando pontualmente alguns de seus textos na tentativa de entendermos o perfil dessa revista. A reconstituição da trajetória da $R L$ foi uma verdadeira atividade de anamnese, a história de uma geração de pessoas que ajudou a fundá-la e a mantê-la, provavelmente num dos primeiros momentos em que aqueles estudantes universitários eram reconhecidos enquanto intelectuais. Por esse motivo, parte deste trabalho destinou-se a refletir sobre a importância que o intelectual exerce na sociedade, enquanto ser politicamente engajado nos meios acadêmico ou artístico, e acerca do valor da arte, enquanto objeto cultural e produto do capital.

Os resultados alcançados por esta pesquisa se apresentaram, na medida do possível, satisfatórios, levando-se em conta o desafio de estudar um tema absolutamente inédito, sem trabalhos acadêmicos sobre o corpus foco deste estudo, que pudessem servir de fonte de consulta para dar suporte 
teórico às críticas aqui desenvolvidas. Em compensação, a sensação de pioneirismo, aliada à superação desse desafio, é extremamente gratificante.

Por esse motivo, devido ao ineditismo desta pesquisa, pela ausência de estudos realizados sobre a $R L$ ou sobre qualquer outro periódico semelhante, gostaria de finalizar este trabalho de forma otimista, com a certeza de que servirá como documento arquivístico, sendo utilizado como fonte de pesquisa para o desenvolvimento de novos trabalhos acadêmicos.

Encerro este trabalho propondo aos pesquisadores o desafio de continuarem explorando esse periódico, propiciando a continuidade deste estudo, pois a revista, enquanto arquivo é objeto em constante (re) construção e (re) leitura, por possuir caráter de obra inacabada, assim definido por Reinaldo Martiniano Marques:

A teorização e o tratamento de fundos documentais existentes em arquivos literários devem estar atentos à natureza heteróclita e híbrida dos materiais e objetos que os constituem, transformando-os num misto de biblioteca, arquivos documentais e museu. Dotados de um caráter aberto, dinâmico, os arquivos estão sempre inacabados, na medida em que podem acolher novos documentos e materiais. Pode-se dizer que são um verdadeiro work in progress. ${ }^{10}$
Aliado a isso (por que não?), uma vez catalogada, que a revista possa, agora, ser digitalizada, reativada, que seja dada a ela maior publicidade, permitindo-se, assim, que possa circular com maior frequência, tanto no meio universitário quanto na sociedade, incentivando o desenvolvimento cultural, o surgimento de novos talentos artísticos e propiciando a circulação de textos e ideias dos discentes.

\section{REFERÊNCIAS}

DERRIDA, Jacques. Mal de Arquivo - uma impressão freudiana. Trad. Cláudia de Moraes Rego. Rio de Janeiro: Relume Dumará, 2001

HUYSSEN, Andreas. Seduzidos pela memória: arquitetura, monumentos e mídia. Trad. Sérgio Alcides. Rio de Janeiro: Aeroplano, 2000

LÉVY, Pierre. Cibercultura. Trad. Carlos Irineu da Costa. São Paulo: Editora 34, 1999. Coleção Trans.

MARQUES, Reinaldo; VILELA, Lúcia (orgs.). Valores: arte, mercado, política. Belo Horizonte: Editora UFMG/Abralic, 2002.

SAID, Edward W. Cultura e política. Trad. Luiz Bernardo Peicás. São Paulo: Boitempo, 2003. (Cap. "O papel público de escritores e intelectuais").

SILVA, Maurício. Consagração e decadência do academicismo literário: o caso do jornalismo. Aletria - Revista de Estudos de Literatura, v. 6, 1998-1999. p. 77-95. 
UNIVERSIDADE FEDERAL DE MINAS GERAIS. Revista Literária

do corpo discente da Universidade Federal de Minas Gerais

(RL). Belo Horizonte: UFMG, 1966-1996.

UFMG, FACULDADE DE LETRAS. Ipsis; Revista Literária do corpo discente da UFMG. Belo Horizonte: UFMG, 2002.

VILELA, Luiz. Os novos: romance. 2. ed. Rio de Janeiro: Nova Fronteira, 1984.

WERNECK, Humberto. 1920-1970: meio século de literatura

mineira nos periódicos. In: Suplemento literário. Belo Horizonte,

p. 33-37. 